\title{
Hypothesis for a more efficient and sustainable development of a district heating in Padova, integrating renewable energies and existing generation plant
}

\author{
Laura Carnieletto ${ }^{1, *}$, Samantha Graci $^{1}$, and Michele De Carli $^{1}$ \\ ${ }^{1}$ Dipartimento di Ingegneria Industriale, Università degli Studi di Padova, 35122 Padova, Italy
}

\begin{abstract}
The present paper shows the background analysis to develop the optimization strategy of a neighborhood heating network sited in Padua, including it in a wider project of district renovation. The case study accounts several different end users: scholastic and offices buildings, a social housing residence and residential buildings.

The analysis starts from a systematic assessment of the buildings, evaluating the need of refurbishment of the envelope and of the distribution system. Further analysis focuses on the optimization of the existing heat generation system, integrating three condensing boilers, with an air to water heat pump and a ground source heat pump, which work more efficiently during base-load periods. The management of the district heating network have been investigated using the dynamic simulation tool TRNSYS, the control strategy of the delivery temperature has been tested based on the outside temperature and verifying to satisfy comfort conditions inside the buildings.

A sustainable solution is the recovery and drainage of rainwater, that can be reused for the toilets' flushing. Therefore, the project solution identified aims at a more rational use of energy sources, which is the simplest and cheapest way to proceed on the decarbonization path that is a mid-term target for the Padua administration.
\end{abstract}

\section{Introduction}

The Italian building stock is one of the oldest in Europe, presenting problems related to seismicity and energy efficiency. The retrofit of these buildings is the new challenge of sustainability. Retrofit of the envelope and of the internal distribution system represents the first significant measure towards energy savings strategies, reducing the energy needs, the supply temperature and consequently the waste of energy sources.

The innovative district heating network designed for a neighborhood in the South part of Padua, aims to consider the district as a component of a larger system, working with different users and energy demands, such as school buildings, residential buildings, touristreceptive buildings, residences for Social Housing, offices and places of worship. This variety has made interesting the design of the district heating network [1] that uses an existing thermal plant and provides for the integration with a groundwater heat pump, more efficient in periods of low load and divided into three main branches managed at different temperature.

The innovative element presented in the project is the recovery of grey water [2] and rainwater, supporting a strong sustainability culture which has been developing in the recent years.
The project is innovative since it represents an opportunity for citizens to develop a new, sustainable and shared culture of living, which must be supported by accurate information and user preparation to give them the opportunity to contribute with their own choices to improve the community. New jobs can also be created for the management and maintenance of the facilities, which involve specific training, and will allow greater integration for low-income people or for immigrants living in the neighborhood. This project therefore undertakes to achieve a global improvement, from the efficiency of the plants to sociality, to guarantee respect for the environment and human health.

\section{Case study}

The site considered is located within the South-East area of the Municipality of Padua. The buildings studied, represented in the block diagram in Figure 1, belong to different end-uses:

- Boarding House for university students and nursery school;

- Primary school;

- Social Housing Buildings;

- University Campus and daily clinic.

\footnotetext{
${ }^{*}$ Corresponding author: laura.carnieletto@phd.unipd.it
} 


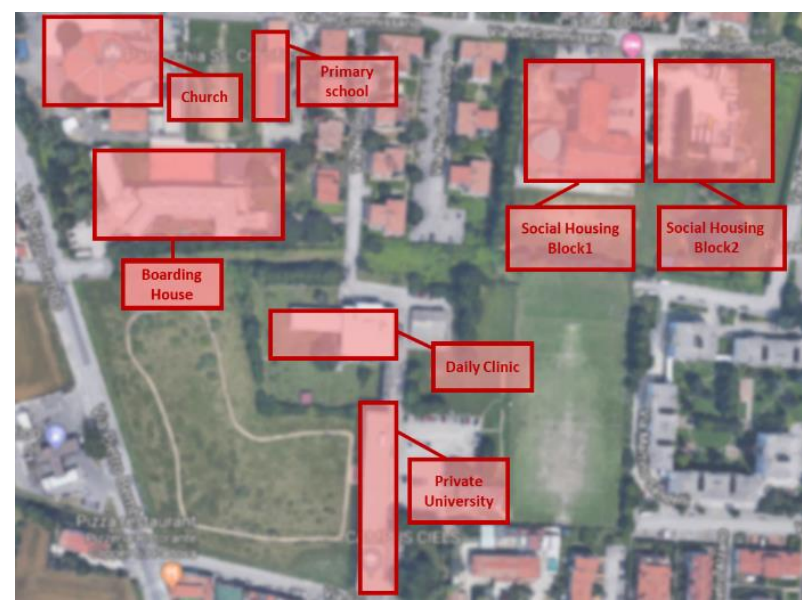

Fig. 1. Buildings involved in the design of the district heating network

To size correctly the district heating network, it is necessary to define as more precisely as possible the characteristics of each building, which in this case study provide very different uses and, therefore, very different trend and magnitude of the energy demand.

The volumes of the individual buildings have been provided by previous and verified studies using the Regional Technical Chart (CTR) [3], which provides an estimate of the surfaces in plan of every single building. These surfaces represent the shape of the perimeter seen from above, but do not represent the exact size of the base area building. Evaluation errors can be due to the presence of overhanging roofs beyond the perimeter walls, but it is almost negligible considering the final aim of the study.

After on-site inspections, plans and heights have been checked to have a reasonable estimation of the gross volumes, including internal and external walls.

A first calculation aims to identify how to share the thermal demand among the district users, estimating also the peak value of the thermal power. The value of 20 $\mathrm{W} / \mathrm{m}^{3}$ has been chosen as average value to calculate the peak power needed to meet the thermal demand, whereas for the Church it has been considered as an average value $45 \mathrm{~W} / \mathrm{m}^{3}$, since the end use is completely different compared to residential or tertiary.
Table 1. Description of the users involved in the distribution of the district heating network.

\begin{tabular}{|c|c|c|c|c|}
\hline Building & Use & $\begin{array}{c}\text { Volume } \\
{\left[\mathrm{m}^{3}\right]}\end{array}$ & $\begin{array}{l}\text { Heating } \\
\text { System }\end{array}$ & $\begin{array}{c}\text { Power } \\
{[\mathrm{kW}]}\end{array}$ \\
\hline \multirow{5}{*}{$\begin{array}{l}\text { Social } \\
\text { Housing } \\
\text { Block1 }\end{array}$} & Offices & $1^{\prime} 474$ & \multirow{5}{*}{ Radiators } & 50 \\
\hline & Social Hotel & $9^{\prime} 130$ & & 183 \\
\hline & $\begin{array}{l}\text { Social } \\
\text { Housing }\end{array}$ & 2442 & & 49 \\
\hline & Restaurant & $1^{\prime} 849$ & & 37 \\
\hline & Offices & 2800 & & 56 \\
\hline \multirow{4}{*}{$\begin{array}{l}\text { Social } \\
\text { Housing } \\
\text { Block2 }\end{array}$} & Block A & 6781 & \multirow{4}{*}{$\begin{array}{l}\text { Radiant } \\
\text { System }\end{array}$} & 136 \\
\hline & Block B & $8^{\prime} 772$ & & 175 \\
\hline & Block C & 8770 & & 175 \\
\hline & Block D & 6788 & & 136 \\
\hline University & $\begin{array}{c}\text { Private } \\
\text { University }\end{array}$ & $11^{\prime} 314$ & Radiators & 290 \\
\hline Clinic & Daily Clinic & $5^{\prime} 538$ & Radiators & 78 \\
\hline \multirow[b]{2}{*}{$\begin{array}{l}\text { Boarding } \\
\text { School }\end{array}$} & Kindergarten & \multirow[b]{2}{*}{$9^{\prime} 012$} & \multirow[b]{2}{*}{$\begin{array}{l}\text { Radiators } \\
\text { /no cooling }\end{array}$} & \multirow[b]{2}{*}{180} \\
\hline & $\begin{array}{c}\text { Female } \\
\text { Boarding } \\
\text { School }\end{array}$ & & & \\
\hline School & $\begin{array}{c}\text { Primary } \\
\text { school }\end{array}$ & $3^{\prime} 614$ & $\begin{array}{l}\text { Radiators } \\
\text { /no cooling }\end{array}$ & 51 \\
\hline \multirow{2}{*}{ Church } & Church & $9^{\prime} 081$ & \multirow{2}{*}{$\begin{array}{l}\text { Radiators } \\
\text { /no cooling }\end{array}$} & 404 \\
\hline & Rectory & 600 & & 17 \\
\hline TOTAL & & 87965 & & 2017 \\
\hline
\end{tabular}

There is a thermal plant which is oversized both in relation to the consumption of registered gas and compared with the design power value obtainable by applying the specific power to the existing volume. The three installed boilers develop a nominal power of 585 $\mathrm{kW}$ each, for a total of $1755 \mathrm{~kW}$, against an estimated power requested to the supplied building of $360 \mathrm{~kW}$. Potentially, supposing to reduce the energy demand improving the thermal insulation of the buildings and substituting radiators with fan coil, the installed power in the thermal plant could satisfy the energy demand of all the buildings considered except for the two blocks belonging to the social housing residence.

The basic idea of the project is therefore to use the installed power as primary energy supply of a district heating network, which connect all the buildings considered. Supposing to consider as favourable condition external temperatures higher than $7.5^{\circ} \mathrm{C}$, the district heating network can be supplied at medium-low temperature $\left(65-50^{\circ} \mathrm{C}\right)$ by a groundwater heat pump (WWHP) [4] in priority operation, meeting the demand of the user until a maximum power of $250 \mathrm{~kW}$, being supported for the remaining power by the boilers of the thermal power plant. The design solution is completed with the installation of two air heat pumps (HP-AW), which will mainly satisfy the heating needs of the new social housing buildings, alternately feeding the existing structures of the association when necessary. 


\section{Dynamic model of the district heating network}

The district heating network model is designed using TRNSYS [5] a commercial code for dynamic simulations able to solve and implement linear and differential equations, maintaining a modular approach.

The purpose of the dynamic simulations is to understand how to optimize the management of the three branches of the network at different temperatures, due to the presence of high temperature and low temperature terminal units.

In particular, both new and retrofitted buildings belonging to the social housing association will be supplied at medium-low temperature, since the they are equipped respectively with radiant floor systems and fan coils. On the contrary, the two branches serving the other users will be managed at medium/high temperature, since it is necessary to satisfy the radiator thermal demand.

The final objectives of the simulations are the quantification of the heat losses along the infrastructure and the evaluation of the return temperature of fluid, known the input temperature and modifying the input parameters to obtain the optimal configuration for the network.

In order to calibrate the simulation models for the evaluation of the thermal energy demand of the buildings, the thermal consumption profiles have been obtained from energy bills; efficiency of the generation system currently in use have been considered.

Assuming that each user's thermal energy demand must be guaranteed, two conditions must be verified:

- the utility substation must exchange enough hourly power;

- the delivery temperature of the secondary circuit must guarantee the performance of the terminal units. Load factors of the building and of the terminal units was compared based on the external temperature and the average operating temperature of the terminals. The final set up of the temperature levels have shown that the operation of the terminal satisfies the thermal energy demand for more than $98 \%$ of the time.

To design the model as much close to reality as possible, the thermal power plant has been integrated to the heat distribution network by means of a dedicated component. In this first phase of the model the contemporaneity of the loads and their variations have not been optimized and the three existing generators are supposed to work in parallel. These condensing boilers allow a modulation up to $20 \%$ of the rated power.

The model was initially implemented at constant supply temperature [5], in order to verify the efficiency of the terminal units during the heating season. Temperature range tested was between $80^{\circ} \mathrm{C}$ and $50^{\circ} \mathrm{C}$ (Fig.2). The model was then implemented varying the delivery temperature during the heating season in the range indicated above; in this phase the time intervals assigned to each delivery temperature are not automatically determined by the calculation code but derive from a series of intervals based on the results obtained in the first set of simulations.

Finally, considering the real annual time profile of the outside temperature, a new design hypothesis has been implemented.

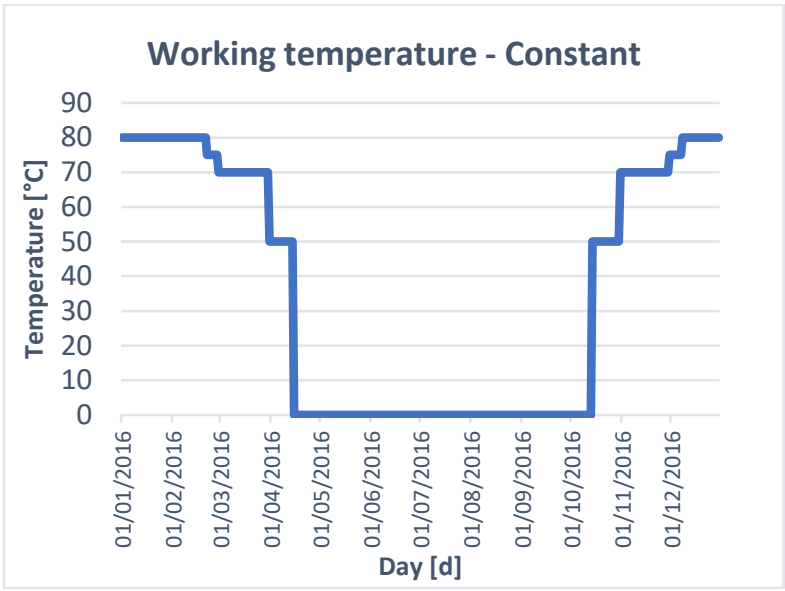

Fig. 2. Constant working temperature

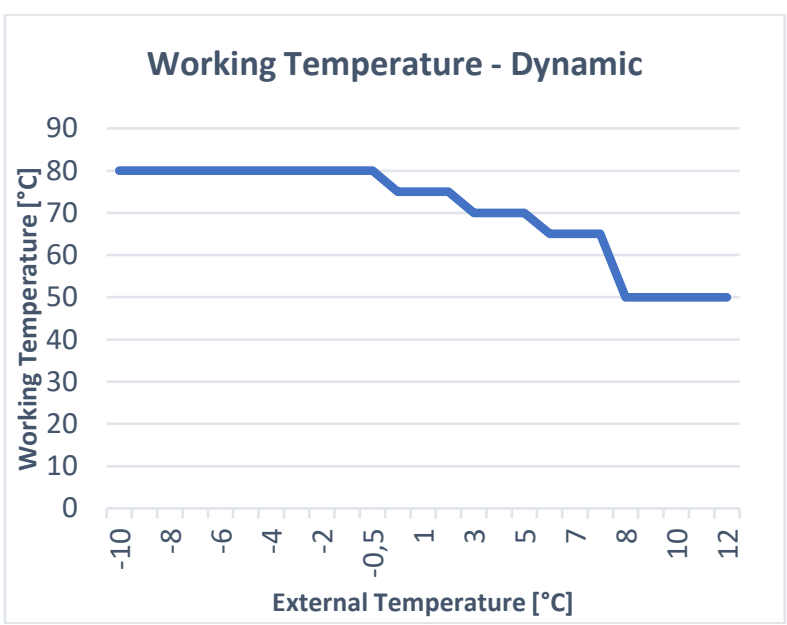

Fig. 3. Dynamic working temperature

The model was modified in order to set the best flow temperature based on the external climatic conditions; the average daily temperature for each day of the year was calculated and correlated to an appropriate flow temperature of the heat transfer fluid, checking the correspondence with the temperature ranges obtained from the climatic curve. In order to control and limit the temperature variation of the network, the external temperature considered was the minimum value between the average temperature of three days and the average daily temperature, verifying that the flow temperature calculated on the average of the three days is slightly higher than that calculated daily only for $6 \%$ of the year. This working logic allows to vary the temperature of the hot fluid varying as a function of the real needs determined by the external temperatures, working no longer at constant values for long and determined period of the year (Fig. 3). Moreover, it allows the hot fluid to work at medium to low temperatures for a greater number of hours, optimizing the operation of condensing boilers. 


\subsection{Hypothesis 1: Separated integration of geothermal heat pump and air to water heat pumps}

The hypothesis of integrating geothermal and air heat pups as primary energy source for the heating network is based on the idea to make them work for as many days as possible.

In fact, when the network can operate at medium to low temperatures, the groundwater heat pump allows to supply the hot fluid at $65{ }^{\circ} \mathrm{C}$, obtaining a seasonal COP of 3.95 if using a cold source at $15{ }^{\circ} \mathrm{C}$. According to the heat demand of the district heating network, the heat pump can work up to a maximum available power of 250 $\mathrm{kW}$, which corresponds to the nominal power of the machine. When the power requested is lower, the residual energy available is shared with the existing and retrofitted social housing residence.

The heating demand of the new buildings belonging to the social housing association, on the contrary, are fully satisfied by air to water heat pumps; moreover, they contribute to the satisfaction of the thermal demand of the existing building when the power that can be supplied by the groundwater heat pump is not enough.

Even if an important reduction in the primary energy required has been calculated, there is an increase in thermal energy which can be attributed to the thermal losses of the network, equal to about $10 \%$ (Table 2) of the total thermal energy.

In conclusion, comparing the percentage of thermal energy supplied by the heat pumps with respect to the boilers, it is evident how this strategy allows to cover almost the $35 \%$ of the annual thermal energy demand of the users (excluding the social residence), with renewable energy sources (Table 2).

Table 2. Comparison between the design solution and the current operating conditions.

\begin{tabular}{|l|l|l|l|c|}
\hline & \multicolumn{2}{|c|}{ Designed Solution } & $\begin{array}{l}\text { Current } \\
\text { solution }\end{array}$ & Comparison \\
\hline & Boilers & WWHP & $\begin{array}{l}\text { Single } \\
\text { system }\end{array}$ & \\
\hline $\begin{array}{l}\text { Thermal } \\
\text { Energy [kWh] } \\
\text { (Ratio [\%]) }\end{array}$ & $\begin{array}{l}479^{\prime} 969 \\
(65 \%)\end{array}$ & $\begin{array}{l}254^{\prime} 481 \\
(35 \%)\end{array}$ & $810^{\prime} 731$ & $\begin{array}{c}\text { Increase } \\
10 \%\end{array}$ \\
\hline $\begin{array}{l}\text { Primary } \\
\text { Energy [kWh] } \\
\text { (Ratio [\%]) }\end{array}$ & $\begin{array}{l}468267 \\
(75 \%)\end{array}$ & $\begin{array}{l}155^{\prime} 967 \\
(25 \%)\end{array}$ & $883^{\prime} 248$ & $\begin{array}{c}\text { Reduction } \\
15 \%\end{array}$ \\
\hline
\end{tabular}

\subsection{Hypothesis 2: Dynamic integration of the heat pumps}

The second hypothesis aims at optimizing the integration between heat generation with the condensing boilers and the heat pumps.

The church in this case will be excluded, in order to have more homogeneous final users and therefore heat demand and thermal load profile. Moreover, the buildings have no longer high temperature terminal units (i.e. radiators), but the hypothesis include the substitution with fan coil for the retrofitted building and the installation of radiant heating and cooling systems in the new buildings.

The model has been modified by using separately the three generators, as indicated by the three different colours in Fig. 2. One boiler is directly connected to serve the private university and the clinic, supplying hot water at $70^{\circ} \mathrm{C}$ which can return at $65^{\circ} \mathrm{C}$. The second must serve the boarding house and the primary school with the same temperatures as before. In this case, if the return temperature is bigger or equal to $55^{\circ} \mathrm{C}$, before starting the cycle it supplies the hot fluid to the social residence until the temperature returning from this second user decreases at maximum to $35^{\circ} \mathrm{C}$, in order to have a low values of return temperature which makes boilers working more efficiently. When the return temperature from the school is lower than $35^{\circ} \mathrm{C}$, ground source heat pumps (GSHP) should be able to satisfy the energy demand of the building, eventually working also with an air to water heat pump. The third boiler is connected to the social housing residence through a fourway valve, so that in case of emergency or maintenance it can be used as backup system.

Implementing this temperature strategy, the social housing residences exploit the heat exchanged by the fluid that has already supplied the necessary heat in the boarding school. Three different levels of temperatures have been investigated, calculating the amount of time temperatures are high enough to supply the radiant heating systems inside the social housing apartments (Table 3).

Table 3. Percentages of time in which temperature levels are satisfied

\begin{tabular}{|l|c|c|}
\hline Temperature & Retrofitted Building & New Building \\
\hline $\mathbf{3 5 ^ { \circ } \mathbf { C }}$ & $96 \%$ & $98 \%$ \\
\hline $\mathbf{4 0}^{\circ} \mathbf{C}$ & $86 \%$ & $94 \%$ \\
\hline $\mathbf{4 5}^{\circ} \mathbf{C}$ & $69 \%$ & $75 \%$ \\
\hline
\end{tabular}

More complex simulations need to be implemented to validate this management strategy and studying the real energy savings, however Table 3 shows that this solution is promising to develop a cascade system supplying the fluid with a temperature of $40^{\circ} \mathrm{C}$ for more than $85 \%$ of the time.

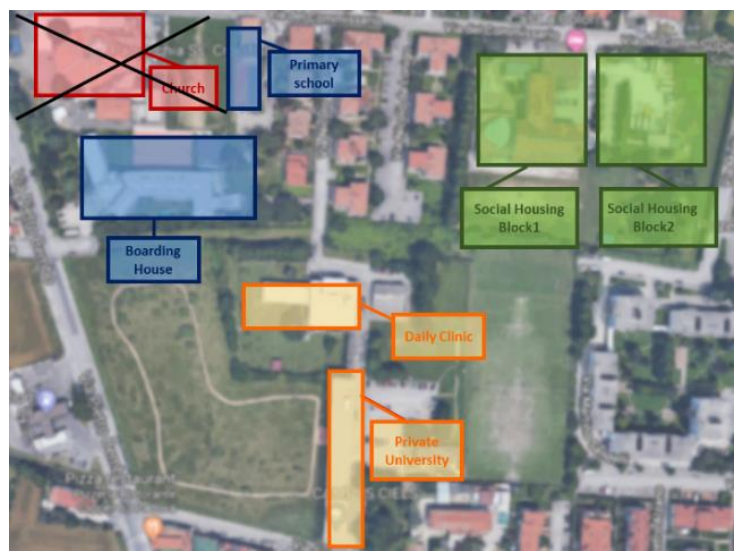

Fig. 4. Buildings involved in the second design hypothesis. The three different colours indicate the users served by each boiler. 


\section{Recovery and drainage of the rainfall}

Supporting a particularly strong sustainability culture developed in the last few years in this neighbourhood, innovative solution to re-use water have been studied. A small application of phytodepuration system has been designed to recover a volume of water needed for flushing the toilets present in the social residences. In Italy, the water collection systems are based on the traditional centralized system, which conveys together all types of waste water (domestic, civil, industrial) into the sewage system to transport them to the purification system, causing a deterioration in the quality of the water, which requires complex and energy-intensive treatments. The grey water that can be collected [2] in this case study corresponds to the fraction that derives from the kitchen drain; they are characterized by large volumes and low pollutant loads, have an alkaline $\mathrm{pH}$ and can be treated with phytodepuration systems that allows to reuse them for non-potable purposes (irrigation, flushing of toilets). The phytodepuration of the water coming from about 100 users has been planned, which can be taken downstream of the grease condensate trap. Due to the small flow of wastewater to be treated [6], a horizontal submerged flow tank may be used [7].

However, the recovery of the waste water from the kitchen, does not satisfy the water request of the 200 toilets in the new and existing buildings of the social housing buildings; assuming a daily consumption of 60 1/inhabitant, the total demand for water amounts to 12 $\mathrm{m}^{3} / \mathrm{d}$, and the dimensioned phytodepuration system would allow the recovery of $4 \mathrm{~m}^{3} / \mathrm{d}$, considering a recovery efficiency equal to 0.9 .

In order to achieve the objective with a view to a philosophy of recovery and reduction of waste, an integration was made by collecting and reusing the rainwater, intercepted by the roof of the new buildings of the social housing association.

The collection and drainage of rainwater is carried out by means of dispersion chambers and a high capacity storage tank. The reinforced structure of the polyester elements composing the tank ensures resistance to heavy loads, allowing the overlying soil to be used for other applications, such as gardens or car parks.

Sand filters at the exit of the storage tank are needed to satisfy hygiene standards to reuse treated water, in order to remove any suspended solids in the fluid. Neglecting the analysis of rainfall, not always constant in Padova especially during the summer season, a first solution was designed to guarantee a 5-day autonomy for users. This hypothesis allows to contain the costs of construction of the tank by collecting a volume of water equal to $40 \mathrm{~m}^{3}$, with a tank of $96 \mathrm{~m}^{2}$. Being more interested in the environmental benefits of the recovery of the water, it is possible to increase the autonomy of the system. However, the operating conditions of the rainwater accumulation system depend on the annual rainfall; therefore, the meteorological data supplied by the Arpav [8], relative to the meteorological station at the botanical garden of Padua for the year 2016, have been elaborated to determine the actual autonomy that the recovery and drainage plant of the rain water.

Considering that rainfalls are mainly characterized by concentrated and intense phenomena, there is no marked difference in the autonomy of the system considering a period of 10 days rather than 5 , while the cost increases significantly.

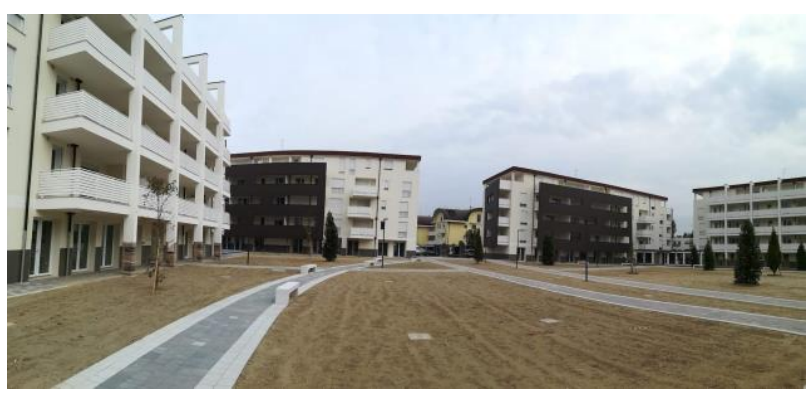

Fig. 5. Photos of the new social housing residences

\section{Conclusion}

The project described aims to suggest a sustainable refurbishment strategy since the redevelopment of the existing building stock is nowadays one of the most relevant issues to achieve a global improvement.

The study conducted for the district located in an area in the south of Padua, shows how the area is well representative, for the type and characteristics of the buildings present, of today's Italian building stock.

The main idea developed is to use the existing thermal power plant oversized with respect to the needs of the users currently served to power a district heating network serving the utilities involved.

Assuming that the energy demand of the users must be guaranteed, various implementations have been made to lower the working temperature of the district heating network, under reduced heat load conditions, (e.g. in the middle seasons, or in the presence of particularly mild outdoor temperatures). Two main hypotheses have been considered in this first analysis. However, a first estimation of energy savings (14\% of primary energy) together with a more rational use of energy sources, integrating fossil fuel generators and heat pumps powered by electricity have been presented.

The analyses carried out concern only heating operation, while further studies are supposed to determine energy savings that could be obtained in the management of cooling.

A better performance could be provided if the grid could be considered as a whole and not as separate buildings, i.e. in a concept of smart grid. Unfortunately, so far it is not possible to share electrical energy between buildings in a common grid and hence it was not possible to estimate the possible saving including a wide system for electric energy.

The two innovative aspects of the project are represented by the recovery of gray cooking waters and rainwater which aims to treat the volume of water needed to flush the toilets present, reducing the amount of water taken from the sewage system. A tank of phytodepuration capable of treating a third of the volume of water required for toilets has been designed for the treatment 
of gray kitchen waters; the residual water demand is supplied by the accumulation of rainwater through a storage system. Several strategies have been studied, varying the autonomy guaranteed by the rainwater recovery system to find an optimal solution of 5-day autonomy, considering also the real precipitation frequency.

\section{References}

[1] Associazione Italiana Riscaldamento Urbano, «Appendice Metodologica. Metodologia utilizzata per la valutazione del risparmio di enrgia primaria e delle emissioni di evitate di anidride carbonica attribuibili ad una rete di teleriscaldamento,» in $\mathrm{Il}$ riscaldamento urbano - Annuario 2015, Milano, Grafteam, 2016, pp. 21-24.

[2] M.C. Lavagnolo, M. Malagoli, L. Alibardi, F. Garbo, A. Pivato, R. Cossu, «Use of oleaginous plants in phytotreatment of grey water and yellow water from source separation of sewage.,» Journal of Environmental Science, n. 55, pp. 274-282, 2017.

[3] Regione del Veneto, Available online: https://www.regione.veneto.it/web/ambiente-e-territorio/cartatecnica-regionale.

[4] A. Cavallini, «Le pompe di calore geotermiche Aermec Spa,» Dipartimento di Fisica Tecnica dell'Università di Padova, Aermec Spa, Padova, 2006.

[5] A. Cerè, V. Tarenzi, «Calcolo del regime stazionario di una rete di teleriscaldamento,» Enidata Spa, cap. 4.9.

[6] J.Vimazal, «Horizontal sub-surface flow and hybrid constructed wetlands systems for wastewater treatment.,» Ecological Engineering, vol. 25, n. 5, p. 478-490, 2005.

[7] B. Pucci, M. Mazzoni, « Elementi utili in agricoltura: Fitodepurazione - Fertirrigazione - Utilizzo dei fanghi. Linee guida per la fitodepurazione dei reflui domestici ed urbani.,» S.Ippolito (PU), 2004

[8] Agenzia Regionale per la Prevenzione e la Protezione Ambientale del Veneto, Available online:

http://www.arpa.veneto.it/previsioni/en/html/meteo_veneto.php». 